\title{
At a crossroads? Key challenges and future opportunities for patient involvement in patient safety
}

\author{
Jane K O’Hara, ${ }^{1,2}$ Rebecca J Lawton ${ }^{2,3}$
}

${ }^{1}$ Leeds Institute of Medical Education, University of Leeds, Leeds, UK

${ }^{2}$ Quality \& Safety Research, Bradford Institute for Health Research, Bradford, UK ${ }^{3}$ School of Psychology, University of Leeds, Leeds, UK

\section{Correspondence to} Dr Jane K O'Hara, Leeds Institute of Medical Education, University of Leeds, Level 7 . Worsley Building, Leeds LS2 9NL, UK;

jane.o'hara@bthft.nhs.uk

Accepted 11 May 2016 Published Online First 22 June 2016

\section{SLinked}

- http://dx.doi.org/10.1136/ bmjqs-2015-004292 - http://dx.doi.org/10.1136/ bmjqs-2015-004839

CrossMark

To cite: O'Hara JK, Lawton RJ. BMJ Qual Saf 2016:25:565-568.
In 2002, Charles Vincent and Angela Coulter published what would become a seminal paper in the field of patient safety. ${ }^{1}$ Their argument was simple and compelling - that patient safety could be improved through the greater involvement of patients and their families. Over the past decade, the healthcare landscape has evolved, with patients and families now firmly placed at the centre of care design and delivery in both policy, and increasingly practice. However, as highlighted in two papers ${ }^{2} 3$ published in this issue of BMJ Quality \& Safety, there remain significant challenges in the meaningful integration of the patient perspective in improving the safety of care. Why does involving patients in safety improvement remain so hard? In this editorial, we propose a number of reasons, before considering some potential future opportunities for improving the involvement of patients and their families.

\section{ACHIEVING GENUINE PATIENT INVOLVEMENT IS CHALLENGING}

Ocloo and Matthews outline a range of reasons why achieving genuine patient involvement presents challenges, before concluding that "current involvement practices at a national and local level often involve a narrow group of individuals...". While their comments mainly relate to the lack of diversity of patient involvement in healthcare improvement, the same can also be said about the representativeness of patients within the very research that seeks to provide evidence to underpin wider involvement. Some of the most vulnerable patients are often excluded from research exploring the involvement of patients in patient safety -for example, patients unable to speak the host country language or frail elderly patients with delirium or dementia. These research restrictions make ethical sense insofar as patients cannot provide informed consent, but they skew the existing empirical literature by excluding the very patients that are most at risk for experiencing adverse events, such as the elderly ${ }^{4}$ and non-native language speakers. ${ }^{5}$ What we know about patient involvement in managing and improving safety therefore might not reflect the reality for some of the most vulnerable patients and their families, limiting generalisability of results and limiting the likelihood that interventions or approaches will lead to meaningful or lasting impact on services.

\section{WE ARE ALREADY AWASH WITH DATA AND DON'T DO ANYTHING WITH IT}

One way to engage patients in patient safety is to ask them to provide feedback about care. A variety of methods are now available internationally for capturing patients' experience of services, levels of satisfaction, and increasingly, their perspective on the clinical outcomes of treatment. Patients are also now routinely invited to present their experiences of healthcare to board-level executives and within education. ${ }^{36}$ Additionally, patients are increasingly finding their own outlets for providing feedback online via dedicated patient websites or social media. ${ }^{78}$ However, despite this ever-expanding well from which to draw the patient perspective of care, the difficulties for staff in using these data as a basis for improving services have become increasingly evident. $^{9}$

Patient feedback represents just one small part of an ever-growing tsunami of data that we collect in health services, but singularly fail to consistently devote time and resources to interpret and act on. In a recent editorial, Donald Berwick explicitly called for a reduction in measurement, ${ }^{10}$ 
reflecting a clear appetite internationally for streamlining the measurement of quality and safety. Such an approach would also shift the emphasis towards gathering more meaningful indicators that have a greater chance of being used as a basis for the management of safety and service improvement, as well as using and linking existing data and machine learning methods for the more efficient capture of data for learning. Put simply, health service staff need the time, capability and adequate resources to gather, interpret and act on data that support local improvement.

\section{FEEDBACK FROM PATIENTS DOESN'T FIT WITHIN OUR CURRENT SYSTEMS FOR UNDERSTANDING RISK}

Health services currently operate in a system where safety is promoted by identifying and attempting to minimise past risks. ${ }^{11}$ Such systems are firmly positioned in a 'Safety 1' approach $^{12}$ within which it is difficult to 'fit' patient feedback about the quality and safety of care. Indeed, in studies where patients are asked to report on safety incidents, much of this feedback (when constricted by the confines of definitions of 'harm' or 'patient safety incidents') may relate more to broader quality of care than safety. ${ }^{13} 14$ Additionally, patients often provide positive feedback about the care that they receive. This presents us with two challenges: how do we use this information for organisational learning when safety is defined as an absence of past harm, and how do we integrate and learn from the presence of high-quality, safe care within our current risk management and assurance processes? Too often this feedback is dismissed as irrelevant or unhelpful. Yet the power of positive feedback for promoting safety, through improving staff morale, for example, should not be underestimated. In summary, restricting patient feedback on safety within our current definitions risks a myopic interpretation of the information patients and their families can provide, and the improvements that can arise from acting on it.

\section{PATIENTS' CARE EXPERIENCES ARE NOT LIMITED BY PROFESSIONAL AND ORGANISATIONAL BOUNDARIES}

A key conclusion from our own work speaking to patients and their families about safety is that their experiences are not neatly compartmentalised into those boundaries that structure our health services. ${ }^{15}$ Patients and their families express their experiences as they have experienced them. To those not working day to day within healthcare, the distinctions between acute, community and primary care are not necessarily clear, and arguably not relevant. The distinctions between an occupational therapist, a nurse, healthcare assistant, doctor or pharmacist are also not always obvious in our multidisciplinary health services. Yet most of our current systems for engaging with patients in understanding their perspective of safety, or involving them or their families in service improvement, are based on splitting experiences down these organisational lines. In addition to creating problems with capturing the realities of care from a patient perspective, such splitting has the potential to obscure, or worse, potentiate the effects of safety failures within different settings. ${ }^{16}$

An example of this is the issue of transition from one healthcare setting to another. This period is a particularly risky time for patients, ${ }^{17} 18$ in part, it might be argued, because of the interactive effect of safety failures in one setting amplifying failures in another. For example, a patient within an acute medical ward who is discharged without proper information about their anticoagulant medication finds themselves back in hospital a few days later with a blood clot because community-based healthcare staff who visit the patient's home do not monitor the self-administration of this medication. While patients and their families might very easily be in a position to provide information about these types of safety failures, ${ }^{13} 1920$ without an integration of this information across their 'care journey', these failures in isolation would risk misinterpretation and a downgrading of the level of harm. Further, a narrow focus on the setting only would result in the wider contributory factors for the failures being obscured, impeding the process of organisational learning and any subsequent service improvement. In summary, patients and their families don't experience care in convenient service-sized chunks. This means that health services need to be more creative in involving patients more actively across systems, pathways and transitions of care. By enabling patients and their families to be more active partners in their care and increasing their role as information conduits, we could make transitions across these services smoother for all.

\section{NOT ALL PATIENTS ARE THE SAME, AND NOT ALL PATIENT INVOLVEMENT IS THE SAME}

The extent to which patients and their families are willing to be engaged more directly in healthcare processes and service improvement activities will naturally vary. Involving patients as partners in ensuring the provision of quality and safe care therefore must by definition not follow a 'one size fits all' approach. Ocloo and Matthews ${ }^{2}$ rightly highlight the need for true partnership in the co-design of healthcare provision to avoid tokenism in a restricted range of activity. However, even this aim risks excluding patients and their families who might be unable or unwilling to engage in a continued, longer-term relationship with those seeking to shape policy or improve services. There is value in involving patients at the level of individual care, the service/organisational level or at the wider system level and in doing so on their terms; in other words, offering different opportunities for 
engagement. For example, when seeking to measure and improve at a service level, it might not be appropriate to focus on either patient narratives or patient surveys, but rather embrace that we might need both 'small stories' and 'big data'. While some patients may want only to complete a 2 min tick-box feedback, others may want to tell their story to the board. In short, it may not be helpful to restrict ourselves to a limited number of ideal 'types' of patient involvement, and that doing so might actually have the effect of impeding efforts to seek and use the patient perspective of care.

\section{CONCLUSION: IS PATIENT INVOLVEMENT AT A CROSSROADS?}

The imperative to involve patients and their families in ensuring the quality and safety of healthcare is now firmly established as a cornerstone of both policy and practice. However, it is our belief that the success of these efforts to involve patients may have been stymied by a number of key challenges. We appear to be at crossroads for patient involvement. Do we proceed with the potentially paradoxical incorporation of the patient perspective into our clinically framed risk management processes, siloed approaches to feedback gathering and challenged service improvement efforts? Or do we engage in radical new approaches where patients and the public are routinely invited into a transparent conversation about the provision of high-quality, safe care?

We propose a new manifesto for involving patients in understanding, measuring and improving the quality and safety of care. First, researchers need to explore ways to engage more meaningfully with vulnerable patient groups to ensure that our empirical base is representative. This may be by supporting the development of longer-term research partnerships, but equally seeking out opportunities to engage with patients and their families on their turf and their terms. Second, healthcare organisations should value, support and provide resources for the act of seeking to engage with patients and their families in the design, measurement and improvement of services. Third, health services internationally must recognise and embrace a more expansive view of safety and risk; one where information about the presence of safety may be integrated equally with measures of past harm. In doing this, different perspectives of safety would be ultimately valued and given credence. Fourth, the demarcations of organisational and professional boundaries should not limit the ways in which we seek to gather, interpret and act on the patient perspective of care. If the patient represents the one common presence across all healthcare encounters within their care journey, services should be open to using their unique insight to understand the complexity of services (and opportunities for safety failures), measure performance and seek to improve. Indeed, patients' involvement across the pathway could serve to bring teams from different healthcare organisations together. Finally, we should let go of restrictive idealised positions about the 'right' type of patient involvement. Just as some parents don't want to sit on the governing board of their local schools, not all patients want to be involved in co-production, joint decision-making about service configuration or even share in decision-making about their own care. ${ }^{21}$ We need a range of equally valued opportunities for patients to be involved at different levels and in differing roles.

In support of this endeavour, within the UK recent guidance has been published for those working in healthcare about different ways of engaging patients in patient safety. ${ }^{22}$ Ultimately, we hope that this is just the start of a more open and honest conversation about what we currently know, but also how far we still have to go to involve patients meaningfully in patient safety. As Donald Berwick puts it-'we need to hear the patient voice at every level even if that voice is a whisper'. ${ }^{23}$

Twitter Follow Jane O'Hara at @janekohara

Acknowledgements The authors thank John Wright for his thoughtful comments on an early draft of this paper.

Contributors JKoH drafted the manuscript. RJL edited the manuscript. Both authors agreed the structure and content outline.

Competing interests None declared.

Provenance and peer review Commissioned; internally peer reviewed.

\section{REFERENCES}

1 Vincent CA, Coulter A. Patient safety: what about the patient? Qual Saf Health Care 2002;11:76-80.

2 Ocloo J, Matthews R. From tokenism to empowerment: progressing patient and public involvement in healthcare improvement. BMJ Qual Saf 2016;25:626-32.

3 Langer T, Martinez W, Browning DM et al. Patient and families as teachers: a mixed methods assessment of a collaborative learning model for medical error disclosure and prevention. BMJ Qual Saf 2016;25:615-25.

4 Sari AB, Cracknell A, Sheldon TA. Incidence, preventability and consequences of adverse events in older people: results of a retrospective case-note review. Age Ageing 2008;37:265-9.

5 Divi C, Koss RG, Schmaltz SP, et al. Language proficiency and adverse events in U.S. hospitals: a pilot study. Int J Qual Health Care 2007;19:60-7.

6 Jha V, Buckley H, Gabe R, et al. Patients as teachers: a randomised controlled trial on the use of personal stories of harm to raise awareness of patient safety for doctors in training. BMJ Qual Saf 2015;24:21-30.

7 Greaves F, Ramirez-Cano D, Millett C, et al. Harnessing the cloud of patient experience: using social media to detect poor quality healthcare. BMJ Qual Saf 2013;22:251-5

8 Rozenblum R, Bates DW. Patient-centred healthcare, social media and the internet: the perfect storm? BMJ Qual Saf 2013;22:183-6 
9 Boiko O, Campbell JL, Elmore N, et al. The role of patient experience surveys in quality assurance and improvement: a focus group study in English general practice. Health Expect 2015;18:1982-94.

10 Berwick DM. Era 3 for medicine and health care. JAMA 2016;315:1329-30.

11 Vincent C, Burnett S, Carthey J. Safety measurement and monitoring in healthcare: a framework to guide clinical teams and healthcare organisations in maintaining safety. BMJ Qual Saf 2014;23:670-7.

12 Hollnagel E, Braithwaite J, Wears, RL. eds. Resilient health care. Farnham, UK: Ashgate, 2013.

13 Ward JK, Armitage G. Can patients report patient safety incidents in a hospital setting? A systematic review. BMJ Qual Saf 2012;21:685-99.

14 Weingart SN, Price J, Duncombe D, et al. Patient-reported safety and quality of care in outpatient oncology. Jt Comm J Qual Patient Saf 2007;33:83-93.

15 O'Hara JK, Armitage G, Reynolds C, et al. How might health services capture patient-reported safety concerns in a hospital setting? An exploratory pilot study of three mechanisms. BMJ Qual Saf 2016. Published Online First: 4 Feb 2016. doi: 10.1136/bmjqs-2015-004260

16 Degos L, Amalberti R, Bacou J, et al. Breaking the mould in patient safety. BMJ 2009;29:338.
17 Naylor MD, Kurtzman ET, Pauly MV. Transitions of elders between longterm care and hospitals. Policy Polit Nurs Pract 2009;10:187-94.

18 Waring J, Marshall F, Bishop S, et al. An ethnographic study of knowledge sharing across the boundaries between care processes, services and organisations: the contributions to 'safe' hospital discharge. Health Serv Deliv Res 2014;2(29).

19 Hernan AL, Giles SJ, Fuller J, et al. Patient and carer identified factors which contribute to safety incidents in primary care: a qualitative study. BMJ Qual Saf 2015;24:583-93.

20 Hernan AL, Giles SJ, O'Hara JK, et al. Developing a primary care patient measure of safety (PC PMOS): a modified Delphi process and face validity testing. BMJ Qual Saf 2016;25:273-280

21 Chewning B, Bylund CL, Shah B, et al. Patient preferences for shared decisions: a systematic review. Patient Educ Couns 2012;86:9-18.

22 Patient Engagement in Patient Safety: A Framework for the NHS. NHS England Strategy and Advisory Group and Sign up for Safety. https://www.england.nhs.uk/signuptosafety/ latest-thinking/ (accessed 10 May 2016).

23 Berwick D. On behalf of the National Advisory Group on the Safety of Patients in England. A promise to learn-a commitment to act. London: Department of Health 2013. http://www.gov.uk/government/publications/berwick-reviewinto-patient-safety (accessed 7 Oct 2015). 